\title{
Tisch Cancer Institute Scholars Program: Mentored Cancer Research Training Pipeline for Medical Students
}

\author{
Kaitlyn Ben-David ${ }^{1,2}$ (D) Jenny J. Lin ${ }^{1,3} \cdot$ James L. M. Ferrara ${ }^{1,4} \cdot$ Janice L. Gabrilove ${ }^{1,4}$
}

Accepted: 27 November 2020 / Published online: 6 January 2021

(C) American Association for Cancer Education 2021

\begin{abstract}
Cancer research has led to unprecedented advances in treatment in recent decades. Physician-scientists have played a crucial role in these advances given their unique perspective at the intersection between basic research and clinical care, though their representation in cancer research has been in progressive decline. Cancer research programs that feature strong mentorship at the medical student level are associated with increased likelihood of alumni choosing a cancer research career path. In an effort to increase the cancer research medical student training pipeline, senior research faculty from the Tisch Cancer Institute (TCI) at the Icahn School of Medicine at Mount Sinai (ISMMS) developed the TCI Scholars Program, a rigorous mentored research training program funding medical students' summer research. This program is currently in its third year and has garnered significant interest among mentors and students alike from all four TCI Cancer Center Support Grant (CCSG)-funded research programs. Herein, we describe the development, implementation, evaluation, and major outcomes of this program.
\end{abstract}

Keywords Cancer research training pipeline $\cdot$ Mentored medical student cancer research $\cdot$ Training $\cdot$ Education

\section{Background}

Cancer is a major contributor to disease burden globally and is currently the second leading cause of death in the USA [1]. Cancer research not only advances our understanding of this clinically significant disease but also is critical to the discovery of new diagnostic tools, treatments, and prevention strategies. Advances in clinical cancer care also require effective translational research to harness discovery science and improve human health. Physician-scientists (MD-scientists) are uniquely qualified to advance medicine by translating basic research discoveries into clinical applications that impact patient outcomes [2]. Physician-scientists require methodologic

Kaitlyn Ben-David

kaitlyn.ben-david@icahn.mssm.edu

1 Tisch Cancer Institute, Icahn School of Medicine at Mount Sinai, New York, NY, USA

2 Icahn School of Medicine at Mount Sinai, New York, NY, USA

3 Division of General Internal Medicine, Icahn School of Medicine at Mount Sinai, New York, NY, USA

4 Division of Hematology and Medical Oncology, Icahn School of Medicine at Mount Sinai, New York, NY, USA training to ask important research questions that are clinically applicable. Nevertheless, according to the NIH PhysicianScientist Workforce Working Group [3, 4] and a systematic review of physician-scientist programs [2], there is increasing concern over a leaky trainee pipeline and a steady decline in MD representation at the forefront of biomedical research. This decline in the MD-scientist workforce is associated with the numerous challenges faced by researchers particularly in the early stages of training and development prior to attaining independence as principal investigators [5]. Consequently, there is a compelling need to train and specifically advance the physician-scientist cancer research workforce constituency in order to assure the next generation of physician-scientist cancer investigators.

Cancer research programs for medical students have been shown to aid students in operationalizing their career plans, and often result in program alumni selecting a cancer research career path [6]. Furthermore, exposure to research early in medical school is recognized as a strong determinant of future career choice [6,7]. Mentorship likewise plays a critical role in shaping medical trainee career paths and is associated with increased mentee research productivity and career satisfaction [8-10]. Exposure to and involvement in research during medical school correlates with future success in securing research funding, participating in research subsequent to graduation, and obtaining research-oriented faculty positions [11]. 
In order to invigorate mentored cancer research training options for medical students early in their training, senior research faculty from the Tisch Cancer Institute (TCI) at the Icahn School of Medicine at Mount Sinai (ISMMS) created the TCI Scholars Program. The program's long-term aim is to advance the physician-scientist cancer research workforce through the development of a rigorous, structured, and closely mentored pipeline program for medical students interested in careers in cancer medicine with a focus on research. Herein, we describe the development of and initial results for this mentored research training program for medical students.

\section{Methods}

\section{Program Development}

All ISMMS students have a research graduation requirement that culminates in a written abstract and poster presentation at the annual Medical Student Research Day. Students typically complete the research portion of this requirement in the summer between their first and second year of medical school and are provided a stipend by the medical school if they work with ISMMS faculty. In years prior to the inauguration of the TCI Scholars Program, students interested in cancer research often explored funded opportunities at other academic and freestanding cancer institutions to fulfill their summer research experience.

In the fall of 2017, the ISMMS medical student Cancer Interest Group identified cancer research training as an area of unmet need. Consequently, the TCI Education and Career Development Committee conducted an informal needs assessment with the group and decided to create a pipeline program to increase and support medical student cancer research capacity at ISMMS. The goal of the program was to provide a structured and challenging 8-week summer mentored-research experience between the first and second years of medical school. The summer research project would be designed to facilitate an optional more extensive year-long research undertaking in the future, ideally under the auspices of a Scholarly Year, taken at the end of the 3rd year and prior to the start of the final year of medical school. For students who choose to pursue this additional future yearlong mentored research endeavor, the foundation of the mentored relationship has already been established through the summer research program. The ultimate long-term goal of this program would be to further advance the academic skill set and research capabilities needed for students to pursue cancer research opportunities following graduation. To make the TCI Scholars Program desirable and competitive with other similar programs, TCI offered a summer stipend of $\$ 5500$, an average of $\$ 2000$ more than the usual medical school summer stipend allotment at our institution. TCI leadership approved the TCI Scholars Program proposal in 2017, provided seed funding for this initiative and the first Request for Application (RFA) was issued in January of 2018.

\section{Application Process}

The TCI Scholars Program was created to provide a meaningful closely mentored-research experience and to inspire students to pursue a future career in cancer research. As such, the program was intentionally designed to attract talented students seriously committed to engaging in rigorous mentored research endeavors with qualified TCI faculty members with established success in fostering the research careers of students and/or other emerging investigators. Students are offered multiple support mechanisms to identify a mentor including a comprehensive mentor database and dedicated track advisor in the field of the student's interest. All first-year students are also required to have a one-on-one meeting with the director or associate director of the Medical School Research Office within the first 3 months of starting first year to help them identify potential mentors within their areas of research interest. Mentors for the TCI Scholars Program commit to mentoring only one student over the summer award period. The application process reflected the rigor demanded by the program and included the following: (1) a 3-page comprehensive project proposal, (2) applicant CV, (3) mentor letter of support indicating the student's research potential and an evaluation of the project, (4) mentor's biographical sketch including a section on the mentor's former trainees, and (5) Institutional Review Board or Institutional Animal Care and Use Committee approval, if applicable.

\section{Application Review}

The review and choice of TCI Scholars was modeled after the National Institutes of Health (NIH) grant review process [12]. A panel of 5-6 senior TCI research faculty served as reviewers and each application had 3 independent reviews. Scores were assigned for overall impact based on three review criteria: (1) potential of the student applicant, (2) mentor track record and demonstrated involvement with project and applicant, and (3) feasibility and approach of proposed project. Reviewer scores were collected and collated prior to an in-person review meeting, during which all applications were discussed.

Students not selected for the TCI Scholars Program were provided with a letter containing detailed suggestions for how to strengthen their research proposal for future applications and were invited to share their work at the mid-summer TCI Scholars Program Works in Progress meeting. This inclusive approach was implemented in order to provide students with valuable feedback that would enable them to become successful applicants for future funding opportunities. 


\section{Program Structure}

To ensure an informative and enriching experience that would foster each Scholar's success, TCI created a formal, and rigorous program structure. The program consists of an introductory Onboarding, a mid-program Works in Progress seminar, and a final formal Symposium. The introductory Onboarding meeting in early May (prior to the close of the medical school's academic year) for each cohort served as a venue for orientation as well as delineated and aligned expectations. All TCI Scholars and mentors were expected to attend this Onboarding, during which the TCI Scholars program directors reviewed the program's format and expectations. This introductory meeting was critical not only for establishing the logistical framework of the program but also for providing a networking platform for mentors and mentees. During this Onboarding session, discussion-based training forums were also held in which mentors and mentees were divided into two groups led by TCI leadership and the responsibilities and deliverables pertinent to each group were explained in detail. Mentors received additional training adapted from the Entering Mentoring curriculum $[13,14]$ led by senior faculty members from the TCI Education and Career Development Committee, who are trained facilitators for this curriculum. The learning objectives of the mentor training curriculum included multiple strategies for improving communication with mentees, aligning expectations and assessing mentee understanding, addressing issues of equity and inclusion in mentoring relationships, and promoting mentee professional development while identifying methods to improve work-life integration.

Midway through the program, in early July, a Works in Progress seminar allowed students to showcase their progress as well as discuss any recent challenges, anticipate potential future pitfalls, and brainstorm possible solutions. In addition, it provided students with the opportunity to practice their scientific presentation readiness and skills. The program culminated in a formal Symposium in October during which TCI Scholars presented their work to the program mentors and leadership as well as faculty and students external to the program.

TCI Scholars were required to submit a final research report in mid-November. Students were provided a template for this 3-4 page final report with detailed descriptions for suggested content for each section as follows: (1) Introduction: relevance of the problem to cancer, work previously done on the research topic, the gap in knowledge, and the research hypothesis; (2) Methods: study design, population, quality controls, data sources, statistical analyses, unexpected pitfalls, and alternative solutions; (3) Results: principal findings (2-4 figure panels or tables), and outcome of the hypothesis test; (4) Discussion: main conclusions, significance of findings, remaining gaps in knowledge, and future directions; and (5) References. This final report, which embodied the format of a manuscript draft, provided the framework to advance the student's scientific writing skills.

\section{Evaluation}

At the close of the program, students and mentors were asked to provide feedback about their experience including suggestions for improvement. The feedback included a questionnaire that captured qualitative data about participants' experience with the program. Survey items included open-ended questions regarding feedback from both students and mentors about the mentor/mentee relationship and research project as well as about the TCI Scholars Program. We also collected quantitative data from students regarding their research related productivity: (1) oral or poster presentation at a national conference, (2) external research grant funding, and/or (3) manuscript (published or accepted for publication).

\section{Results}

\section{Applicants and Scholars}

Since the launch of the TCI Scholars Program, 21 mentored research proposals were reviewed that reflected all four TCI Cancer Center Support Grant (CCSG)-funded research programs, including Cancer Mechanisms (CM), Cancer Prevention \& Control (CPC), Cancer Immunology (CI), and Cancer Clinical Investigation (CCI) (Table 1). Three scholars per year were selected in the first 2 years, and two scholars were selected in the third year (overall acceptance rate over 3 years of $38 \%$ ). Of note, there were fewer applications than anticipated for the program in 2020 due to challenges resulting from the COVID-19 pandemic. The program has selected projects that encompass an array of research categories reflective of TCI scientific program strengths, and has selected a diverse group of students (Fig. 1): 50\% self-identify as women, $50 \%$ are White, $37.5 \%$ Asian, and $12.5 \%$ Black.

\section{Evaluation}

One hundred percent of students indicated that they would participate in the program again and would recommend the program

Table 1 Distribution of TCI Scholars Program applications by research program

\begin{tabular}{llllll}
\hline & CM & CPC & CI & CCI & Total \\
\hline 2018 & 3 & 1 & 1 & 2 & 7 \\
2019 & 3 & 3 & 1 & 3 & 10 \\
2020 & 0 & 0 & 1 & 3 & 4 \\
Total & 6 & 4 & 3 & 8 & 21 \\
\hline
\end{tabular}

$C M$, cancer mechanisms; $C P C$, Cancer Prevention \& Control; $C I$, Cancer Immunology; $C C I$, Cancer Clinical Investigation 
to others. Additionally, all students reported that mentorship was exceptionally strong in the program and afforded them consistent guidance and instruction throughout the summer as well as a platform upon which to build a broader project. Feedback also captured aspects of the program amenable to improvement, enabling it to evolve. For example, feedback from a TCI Scholar from the first cohort stated:

"While the summer Scholars Program was well organized and executed, there are a few minor issues that could be improved... it would be helpful to know dates, deadlines and exact expectations that pertain to each a bit more in advance"

In response, these suggestions were incorporated into the program by making several adjustments including developing a comprehensive timeline and PowerPoint templates for the Works in Progress and final presentations as well as a written outline template for the final written report.

Feedback identified a need for more formal training in statistical methods. Comments from the second cohort in 2019 included:

"I started with zero experience with STATA, but by the end of the summer, I was able to use it proficiently"

" $\mathrm{R}$ is becoming essential for data analysis. It could be helpful for future students to have a solid background in R"

As a result of these suggestions, starting with the 2020 cohort, the program will be providing a range of resources for biostatistics programming support. Additionally, program leadership is exploring the possibility of developing a more robust didactic curriculum that would include sessions on a variety of topics such as the following: basic programming in statistical software, biostatistics, cancer biology and immunology, and disparities in cancer treatment. The aim of this curriculum would be to expose students to an array of topics that pertain to the
Table 2 TCI Scholars Program alumni (2018 and 2019) achievements

\begin{tabular}{llll}
\hline Student & $\begin{array}{l}\text { Oral or poster } \\
\text { presentation at } \\
\text { national conference }\end{array}$ & $\begin{array}{l}\text { External } \\
\text { research grant } \\
\text { funding }\end{array}$ & $\begin{array}{l}\text { Manuscript (published } \\
\text { or accepted for } \\
\text { publication) }\end{array}$ \\
\hline 1 & Yes & No & No \\
2 & Yes & Yes & No \\
3 & No & No & Yes \\
4 & Yes & Yes & Yes \\
5 & Yes (2) & No & Yes \\
6 & Yes & No & No \\
Total & 6 & 2 & 3 \\
\hline
\end{tabular}

epidemiologic, basic, clinical, and translational fields of cancer research and to offer support from experts in a particular discipline should students seek further guidance and training.

\section{Return on Investment}

The short-term goals of the TCI Scholars Program include the successful completion of the proposed project as well as external achievements that further indicate the strength of the students' projects. The early return on investment for the TCI Scholars Program based on the six students from the first two cohorts is demonstrated by participants' achievements including procurement of externally funded grant awards, oral and poster presentations at national conferences, and published manuscripts (Table 2). We will continue to track TCI Scholars Program alumni over time after graduation to assess their involvement in cancer research during residency and further into their careers.

\section{Discussion}

The TCI Scholars Program, designed to provide opportunities for medical student mentored cancer research, has been a

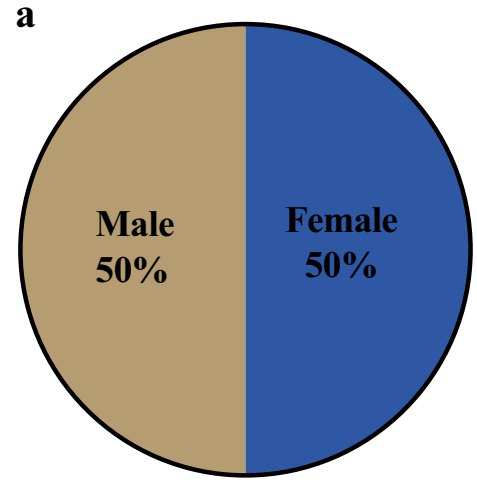

b

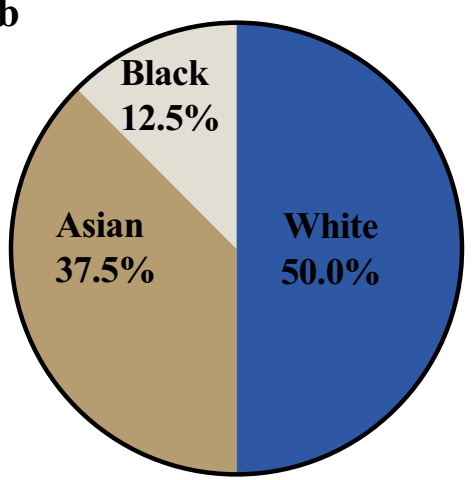

c

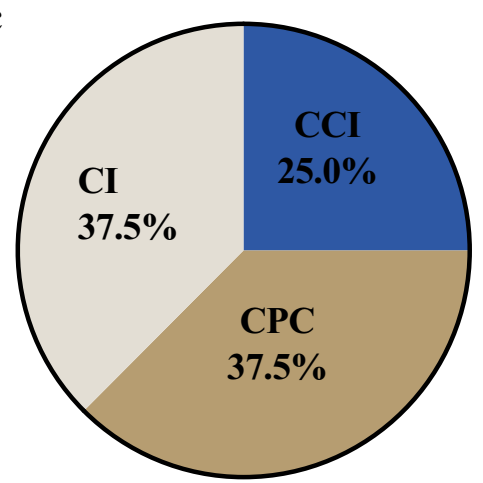

Fig. 1 Distribution of TCI Scholars by percentage of a gender, b race, and $\mathbf{c}$ research program. CPC, Cancer Prevention \& Control; CI, Cancer Immunology; CCI, Cancer Clinical Investigation. Figure generated using Prism Version 9.0.0 (86) 
successfully developed, implemented, and disseminated at ISMMS. Critical research-related markers of students' ultimate career paths include continued research involvement, research publications (both manuscripts and abstract submissions), grant funding procurement, and in the case of clinicaltranslational investigators, advocating comprehensive patient education about the clinical trials they lead [11].

The TCI Scholars Program deliberately incorporated several activities to provide foundational tools for students to hone their research skills. The Works in Progress seminar allowed students to practice their oral presentation skills, and encouraged students to try to foresee any potential obstacles for their project as well as brainstorm ways to overcome research challenges. The final Symposium enabled the scholars to further develop their oral presentation skills and served as a vehicle to facilitate collaboration and cross talk among clinical and basic science researchers and trainees. As TCI Scholars make presentations from a variety of disciplines (Appendix Table 3), the final Symposium helped to highlight a valuable aim of cancer research education to foster multi-disciplinary translational research endeavors [15]. Lastly, a pillar of the program was strong mentorship, which is foundational for career success in research. Mentors in the program all underwent a mentor training seminar as described in the Program Structure above.

Through robust student and mentor feedback, the program has garnered significant interest among ISMMS students as well as TCI research faculty who are interested in mentoring highly motivated students focused on cancer research. These positive perceptions led to continued funding for the program in subsequent years. The TCI Scholars Program is now entering its third year and has been steadily evolving. Long-term follow-up using an annual alumni post-graduation survey is planned to assess their future plans and track continued cancer research undertaken by TCI Scholars alumni; however, their continued research progress and accomplishments thus far are encouraging indicators of the program's potential for cultivating future MD Physician-scientist cancer researchers.

Acknowledgments We would like to thank Ramon Parsons and Sharon Mias for Tisch Cancer Institute (TCI) (P30CA196521) funding of the program. We would further like to acknowledge: the National Cancer Institute (NCI) P30 Cancer Center Support Grant (CCSG), TCI Education and Career Development Committee (ECDC), ISMMS Patient-Oriented Research Training and Leadership (PORTAL) Program (TL1 TR001434), American Society of Hematology (ASH) Medical Student Physician-Scientist Award, our program mentors: James L. M. Ferrara, Constantinos G. Hadjipanayis, Hank Schmidt, Keith M. Sigel, and Juan Wisinivesky and Rhaisili Rosario for her administrative support. The content is solely the responsibility of the authors and does not necessarily represent the official views of the National Institutes of Health. Research reported in this publication was supported by the National Cancer Institute of the National Institutes of Health under award number P30 CA196521 and the National Center for Advancing Translational Sciences of the National Institutes of Health under award number TL1 TR001434-05.

\section{Appendix}

Table 3 TCI Scholars Program project titles and research programs

\begin{tabular}{|c|c|c|}
\hline Student & Project title & $\begin{array}{l}\text { Research } \\
\text { program }\end{array}$ \\
\hline 1 & $\begin{array}{l}\text { The Efficacy of Photodynamic Therapy in } \\
\text { Combination with Radiation Therapy and } \\
\text { Chemotherapy in an Orthotopic Mouse } \\
\text { Glioblastoma Model }\end{array}$ & CCI \\
\hline 2 & $\begin{array}{l}\text { Evaluation of Anal High-Grade Squamous } \\
\text { Epithelial Lesions in Patients Infected with } \\
\text { Human Immunodeficiency Virus }\end{array}$ & $\mathrm{CPC}$ \\
\hline 3 & $\begin{array}{l}\text { Biomarker Monitoring in High Risk GVHD } \\
\text { Patients }\end{array}$ & $\mathrm{CI}$ \\
\hline 4 & $\begin{array}{l}\text { Prophylactic Versus Reactive Feeding Tube } \\
\text { Placement for Squamous Cell Carcinoma of } \\
\text { the Head and Neck }\end{array}$ & $\mathrm{CPC}$ \\
\hline 5 & $\begin{array}{l}\text { Outcomes Following Stereotactic Body } \\
\text { Radiation Therapy in Older Patients with } \\
\text { Non-Small Cell Lung Cancer }>5 \mathrm{~cm} \text { in Size }\end{array}$ & $\mathrm{CPC}$ \\
\hline 6 & $\begin{array}{l}\text { A Response Biomarker for the Treatment of } \\
\text { Acute GVHD }\end{array}$ & CI \\
\hline 7 & $\begin{array}{l}\text { Risk Reduction Strategies in Patients at Increased } \\
\text { Risk of Breast and Ovarian Cancer }\end{array}$ & $\mathrm{CCI}$ \\
\hline 8 & $\begin{array}{l}\text { Evaluation of Elafin as a Prognostic Marker in } \\
\text { Acute Graft-Versus-Host Disease }\end{array}$ & CI \\
\hline
\end{tabular}

$C P C$, Cancer Prevention \& Control; $C I$, Cancer Immunology; $C C I$, Cancer Clinical Investigation

\section{References}

1. Siegel RL, Miller KD, Jemal A (2020) Cancer statistics, 2020. CA Cancer J Clin 70(1):7-30. https://doi.org/10.3322/caac.21590

2. Kosik RO, Tran DT, Fan AP, Mandell GA, Tarng DC, Hsu HS, Chen YS et al (2016) Physician scientist training in the United States: a survey of the current literature. Eval Health Prof 39(1): 3-20. https://doi.org/10.1177/0163278714527290

3. Williams CS, Iness AN, Baron RM, Ajijola OA, Hu PJ, Vyas JM, Baiocchi R, Adami AJ, Lever JM, Klein PS, Demer L, Madaio M, Geraci M, Brass LF, Blanchard M, Salata R, Zaidi M (2018) Training the physician-scientist: views from program directors and aspiring young investigators. JCI Insight 3(23). https://doi. org/10.1172/jci.insight. 125651

4. NIH. Physician-Scientist Workforce Working Group Report 2014. https://acd.od.nih.gov/documents/reports/PSW_Report_ACD 06042014.pdf. Accessed

5. Gordon R (2012) The vanishing physician scientist: a critical review and analysis. Account Res 19(2):89-113. https://doi.org/10. 1080/08989621.2012.660076

6. Desmond RA, Padilla LA, Daniel CL, Prickett CT, Venkatesh R, Brooks CM, Waterbor JW (2016) Career outcomes of graduates of R25E short-term cancer research training programs. J Cancer Educ 31(1):93-100. https://doi.org/10.1007/s13187-014-0786-8

7. O'Sullivan PS, Niehaus B, Lockspeiser TM, Irby DM (2009) Becoming an academic doctor: perceptions of scholarly careers. 
Med Educ 43(4):335-341. https://doi.org/10.1111/j.1365-2923. 2008.03270.x

8. Steiner JF, Curtis P, Lanphear BP, Vu KO, Main DS (2004) Assessing the role of influential mentors in the research development of primary care fellows. Acad Med 79(9):865-872. https:// doi.org/10.1097/00001888-200409000-00012

9. Sorkness CA, Pfund C, Ofili EO, Okuyemi KS, Vishwanatha JK, Nrmn team, Zavala ME et al (2017) A new approach to mentoring for research careers: the National Research Mentoring Network. BMC Proc 11(Suppl 12):22. https://doi.org/10.1186/s12919-0170083-8

10. Horn L, Koehler E, Gilbert J, Johnson DH (2011) Factors associated with the career choices of hematology and medical oncology fellows trained at academic institutions in the United States. J Clin Oncol 29(29):3932-3938. https://doi.org/10.1200/JCO.2011. 35.8663

11. Zier K, Friedman E, Smith L (2006) Supportive programs increase medical students' research interest and productivity. J Investig Med 54(4):201-207. https://doi.org/10.2310/6650.2006.05013

12. Lindner MD, Vancea A, Chen MC, Chacko G (2016) NIH peer review: scored review criteria and overall impact. Am J Eval 37(2): 238-249. https://doi.org/10.1177/1098214015582049
13. Pfund C, House SC, Asquith P, Fleming MF, Buhr KA, Burnham EL, Eichenberger Gilmore JM, Huskins WC, McGee R, Schurr K, Shapiro ED, Spencer KC, Sorkness CA (2014) Training mentors of clinical and translational research scholars: a randomized controlled trial. Acad Med 89(5):774-782. https://doi.org/10.1097/ACM. 0000000000000218

14. Pfund C, House S, Spencer K, Asquith P, Carney P, Masters KS, McGee R, Shanedling J, Vecchiarelli S, Fleming M (2013) A research mentor training curriculum for clinical and translational researchers. Clin Transl Sci 6(1):26-33. https://doi.org/10.1111/cts. 12009

15. Welch DR, Antalis TM, Burnstein K, Vona-Davis L, Jensen RA, Nakshatri H, Riegel AT, Spitz DR, Watson DK, Weiner GJ, The Cancer Biology Training Consortium (2015) Essential components of cancer education. Cancer Res 75(24):5202-5205. https://doi.org/ 10.1158/0008-5472.CAN-15-2077

Publisher's Note Springer Nature remains neutral with regard to jurisdictional claims in published maps and institutional affiliations. 